\title{
The edge of the [dis]order
}

\author{
R. Barelkowski \\ West-Pomeranian University of Technology, Poland
}

\begin{abstract}
This paper discusses the issues of sustainability in the context of the relationship between the city and suburban areas. As a critical contribution, it focuses on a brief diagnosis of the current quality of urban space, an interpretation of the notion of sustainability, factors determining the connection between suburbs and the city, and, last but not least, possible key elements to be acknowledged in strategies of urban development. The work aims to supplement the perception of problems of local-scale planning, attempting to evaluate difficult choices to be made in order to conform to the conditions of sustainability.

Keywords: suburban areas, urban development, sustainable city, planning strategies.
\end{abstract}

\section{Introduction}

There was a time when the centre of a city determined its future. Vital areas of entrepreneurial developments provided fertile ground to locate places which absorb social and cultural life. Significance and prestige were inextricably associated with particular, central spatial locations within cities, and it was the existing space of the city that determined the potential of the place. Since that time the situation has drastically changed, erasing the importance of the continuity of space manifested in attempts to develop urban structures in an evolutionary and harmonious way. Using this kind of generalization a variety of cases may be included even in the 19th century Paris was being transformed by Haussmann in an uncompromised manner as the old order was being replaced intentionally by the new one [1, pp. 717-723 ].

At the time of the Paris public works however, a coincidence of emerging planning issues, the planning profession (regardless of its title which is so distant from contemporary concepts of urban design and town planning) and the escalation of dynamic processes within large urban agglomerations has laid the 
foundation for a future idea of action planning, or reactive planning. The reductionist approach, presented for example in mid 19th century London, had established an institutional appreciation for laissez-faire city managing, focusing selectively on a few of the many problems plaguing the capital of Britain in those times [1, pp. 657-658, 707-705].

The roots of these diverse approaches to city planning, to urban development, determine the range of responses to contemporary problems of the city. The expansion of the late 19th city which was the result of mass transportation, both in Europe and in North America, chaotic and uncontrolled migration of new inhabitants to urban centres in South America, Africa, and Asia in the 20th century, as well as conflict between technical and infrastructural space and inhabited space observed worldwide due to the drastically increased demand for media, energy and individual means of transportation, did not change this dualistic clash of attitudes - response-driven and anticipative planning.

The contemporary concept of a sustainable city is seen as a remedy, its implementation a way to rectify the conditions of urban life and environments. One of the fundamental problems it faces lies in its unavoidable struggle with urban sprawl, including all of its social and spatial consequences. The other one can be found in the dispersed and fragmented management of space, resulting in a limited ability to correlate local policies of various bodies and avoid exceptive tendencies both within the city and outside its administrative borders, in the surrounding area or even region.

\section{The conditions of urban development}

The vagueness of the notion of sustainability, widely criticized as it was defined by World Commission on Environment, cannot be clearly interpreted despite the attempt to clarify it undertaken by IUCN/UNEP/WWF improving the quality of human life while living within the carrying capacity of supporting ecosystems [2] and subsequent redefinitions. The notion itself is overused and diversely interpreted throughout the world and appears to be utilized more as a politically correct label than as a source of pragmatic philosophy with application supported by a scientific apparatus. Thus the ability to implement it is weakened and encourages loose concepts claiming that instead of overcoming it we should embrace it and harness it for the benefit of urban structures. Accepting the spontaneity of urban development and applying just slight touches to the directions in which cities evolve has its strong and objective arguments, but it unfortunately overlooks the problems of existing structures, functioning societies and their needs, social risks and economical encumbrances, and most of all the balance of resources on the side of the environment, not the civilization alone (selectively).

Seeking the methods to manage the gargantuan expansion of metropolitan areas and significant consumption of rural areas combined with the depletion of their potential to generate the most optimal resources for the nearby city (in terms of sustainability), town planners have the option to choose a permissive approach to accept, absorb and legitimize dynamic, chaotic growth and 
dispersion of built areas, or to struggle with these tendencies, attempting to tame the uncontrolled sprawl, to find countermeasures to the dispersion, homogenization and weakening of urban structures. Yet for the first time in the history of civilization the fate of the city will probably be sealed not in its centre, but in suburban areas. The balance of open areas, or, to be more precise, natural environments and areas spared from the direct pressure of urban development, will determine and validate the implementation of sustainable policies.

The peripheral areas of the city have become more and more prominent and significant to its condition while its development manifests the tendency to be deterritorialized [3]. The more traditional, hierarchical structure, explicit in exposing either distinct functional zones or simply the socio-economic status of particular quarters is eroded and undermined by the principle of accessibility, which in comparison with the distribution of population and land value encourages first to transfer vital nodes of urban life away downtown, and second to treat those new nodes as temporary, ready to be removed to new place when accessibility and connectivity terms will dictate.

The edge of the city demonstrates crucial urban development tendencies and contemporary principles of self-driven growth. The situation is paradoxical because first of all global processes at the same time allow for and are required to achieve coordination of efforts to shape conditions of sustainability (whatever definition we intend to acknowledge), as they are responsible for negative processes of dispersion, land consumption, decentralization of cities, policy bending, to include only some of the unwanted phenomena recently observed worldwide for at least fifty years. One has to agree with Zaera Polo who diagnosed over a decade ago the reasons behind urban chaos. The power of the market clashes with the power of political authority and wins, producing unsustainable business networks causing the city to become a place of incoherency, social conflicts, spatial contradictions [4]. The best exemplification of this kind of unsustainability is the management of resources within the EU which is the product of political agreement instead of a reliable assessment of local assets to be used locally [5]. As a result politicians decide who can harvest particular type of crops, who can angle particular species of fish and where geographically, instead of moderating these processes based on environmental data. Another example may be seen in cities which are not forced to rely more and more on local agricultural assets available at hand and instead are constantly motivated to develop, to grow - finally to expand, expressing business trends to perpetually achieve better qualitative results.

Another paradox lies in the nature of the city itself - the more the idea of the city is well-ordered but abstract, assuming it is used to manage real processes, the more the physical substance of the city is organized properly. And the opposite - the more decision-makers focus on the physical aspects of the operation of the city, taking preference for those over the idea, the more ephemeral and uncontrollable the shape of the city becomes. The virtual is subjugating the real. It utilizes the implementation of information technology and the pleasure derived from the optimistic future perspectives. On one hand a significant number of thinkers defined contemporary tendencies of urban 
development as the demand of heterogeneity over alleged homogeneity as the primacy of change and mobility over continuity and stability encouraged the reforming of social policies [6], and on the other hand these catchy slogans were unexpectedly and unintentionally reinforced by the overwhelming contemporary power of social statistics, which deal with the undefined that is trying to be described by the parameters. The measure of success is read in numbers instead of in reality and nowadays we rarely see the urban processes which are ahead of their time.

The third paradox has already been mentioned, which is the potential of unbuilt areas around the city and their quality that reflect and partially determine the conditions of sustainable development for the city. Provocatively saying that the empty determines the quality of the developed, or the untouched defines the quality of the transformed. The periphery, the open areas, rural areas, border settlements constitute a crucial condition for any city to maintain its identity, to emphasize its borders and spatial character, to protect the capacity of spatial systems necessary to facilitate spatial conditions for social life, both current and future. Naturally, the importance and the cultural potential of municipal centres is not to be underestimated, but it forms merely one or a few issues at stake among multiple peripheral problems which have a powerful impact on the condition and sustainability factor of urban structures.

The fourth paradox in the perception of urban development is the abolition of the issue of responsibility. Sustainable development cannot be processed without an honest summary of various factors and conditions responsible for it.

\section{The sustainability of the edge of the city}

Each time we implement the concept of sustainability, due to the ephemerality of its definition, we have to rethink it to understand and to use this notion in every particular case. This is the case of the edge of the city as well. The suburban areas are a training ground, or even a showcase of a contemporary city, which in the majority of examples may be evaluated as chaotic and unsatisfactory, to use moderate words.

One may argue that the sustainability of the city should be described as complex phenomena that conjointly condition urban existence, determining the resources that can be used without being depleted in a way that is most efficient socially, culturally, and environmentally. The definition of spatial sustainability of the city has to be supplemented with the requirement to formulate the balance between the demands and generated values, to appoint an area the city must maintain to be self-sustaining without compromising ecosystems in its zone of influence. The city must impose (on itself) restrictions of maximum development capacity on the area of its influence is able to absorb and, if exceeded, be able to reorganize its development exchanging parametric growth for quality improvement, otherwise the idea of preserving the potential for future generations to meet their needs will be an empty slogan. It is therefore expected that in order to establish sustainable mechanisms the city should be able to produce and successfully utilize the system allowing for permanent control over 
the social, economic, and spatial processes within the area of its influence and to manage the available resources within the limits of maximum development capacity.

No city can ever be claimed as truly autonomous or independent in its management of resources. Every city may thrive only when establishing proper and mutually beneficial links with its peripheries, suburban areas. This, however, cannot be achieved, if urban structures flood the suburban space, instead, shortsightedly, the benefits of development, saturation of infrastructure, network of local and regional roads will deteriorate the environment and at the same time conditions of social life for many decades.

What's more, administrative boards of large agglomerations still often do not perceive the necessity to negotiate the conditions of their functioning with suburban communities, tending to impose a policy of power which is (or just seems) stronger in terms of population and economy. Similarly, administrative bodies of local communities rely on small populations and many times feel as if they are forced to compete with municipalities to gain access to economical sources and as a consequence find themselves formulating their goals in opposition to those defined by the city.

The sustainability of the city may be achieved through simultaneous processing of multiple goals. Due to the fact that a significant part of urban structures of the contemporary city are already established, primarily in its core, central zones, some areas are often accredited as included in preservation programmes or zones, and the physical tissue of the city is built or mostly built, resulting in the filling of central quarters, peripheral interventions are easier, cheaper, affect larger surfaces and offer a wider variety of transformations. While city centres are still capable of reconfiguring and adapting to contemporary and future needs, rarely can this be acquired without similar processes in the suburbs, and suburban space appears to be at the same time less and more risky. On one hand, suburbs may be seen as supplementary areas of various importance, even highly privileged, but still relatively limitedly responsible for the identity of the city. Development of these places influences the cycle of urban life, it can weaken or strengthen the city, but it can be controlled more easily. However, larger open spaces, frequent untamed possibilities of manipulating the programme, typology, and density may result in suburbs being prone to concentrated, short term pressure of developing parties, especially when being overlooked by the authorities and improperly regulated. The temptation to stimulate socio-economical growth in areas which have evidently lower impact on the entire city structure than core areas, followed by the liberation of spatial regulations, decrease of efforts to simulate the whole complexity of results and transformations in urban processes (to reduce the costs of development preparation), on the other hand, can lead to the distortion of a large portion of the urban structure, proving that sometimes unchecked limited interventions affect the city much more than was implied and expected. Thus the establishment of the strategy for suburban areas determines the efficiency of sustainability of the whole city. 


\section{Organizing the [dis]order of the edge of the city}

The implementation of sustainable strategies to manage the development, or to be more precise, the evolution of the city, makes it necessary to define goals which can be unambiguously verified. Despite the inconclusiveness of many factors considered within the term "sustainability", environmental, social, as well as cultural gains can be observed and diagnosed to include assumed results and parameters in the process and to audit and to prove the real ones.

Some tendencies, phenomena, and parameters refer to all aspects of urban life, others refer to one or a few. The first proposed measure is the reduction of resource consumption per urban unit. Contemporarily and paradoxically in most cases we prefer to observe the increase in energy consumption, land consumption, and as a result the total of resources consumption per area instead of gaining solid results in restricting it. It is necessary to notice that the reduction we discuss here is one achieved within municipal infrastructure, not necessarily affecting the consumption rate of particular inhabitants, although the latter also contribute to the whole balance of the system. The most important, however, is not to impede inhabitants' living conditions, but to control the quality of their life and purposefully establish the optimal number of resources assigned to their disposal. Therefore the reduction of resources consumption (RRC) per unit must be correlated not only with area, but with population density as well.

The second component of the possible strategic mechanism is prioritizing the development of urban systems and infrastructure (PUD) with regards to elements which can be reformed, refurbished, or established to obtain a measurable reduction in environmental, social or cultural "costs" of the system's maintenance and operation. This particular factor can be applied to the entire performance or related to area indicator, depending on the specificity of the system and its development. The municipalities should therefore focus on the systems that immediately guarantee the abovementioned gains without aggravating the other fields of influence.

The third strategic element is to attribute urban nodal points, or significant urban areas particularly responsible for urban potential, with adaptability. The radical and dynamic changes we face today in urban life, relocation of functions, relocation of development areas, mobility, social fluctuations in composition, questionable stability of the marketplace, all these factors encourage implementation of spatial buffers against uncertainty - areas to contain adaptability in already established and planned nodal points in urban structure. The adaptability of urban nodes (AUN), regardless of whether they are included in built substance or in vacant spaces, allows for future changes and transformations depending on the course of events and tendencies the city will be forced to face.

The fourth element of the strategy is to maintain the integrity of urban tissue (IUT). This simple condition is very fragile, while the integrity may be seen only as a result of urban processes, not as a mere relationship between physical structures. This feature of urban space is strongly linked to the fifth component, the maintenance of proportions among particular types of spaces (PTS) in the 
city. This linkage may be seen as a manifestation of IUT in PTS, but reciprocally, PTS may affect the integrity, gaining partial independence in the performance of the city. Both characteristics display how harmonious connections of spaces, connection of structural elements, but also that of social groups, information transfers and other phenomena are within the city. Both elements are crucial for conditioning the edges of urban structures, for suburbs as - at least for some time - transitory spaces, because most often their origin cannot be connected to intentional contribution to the urban identity, resulting in purposeful determination of future tendencies and development directions of the area. The suburban area is rather seen as supplementation of the urban structure (which is correct), not as relatively autonomous content. The error in this kind of planning lies in the negligible assumption that the edge of the city almost cannot have the identity, the purpose, the urban value beyond as a parasite to the host. Instead of this the edges of urban structures (not only the suburbs, but all perimeters, also those closer to the centres) should be seen as places to allocate permanent values to and to define their role in the whole system - in the city and outside its administrative borders, especially when related to border areas.

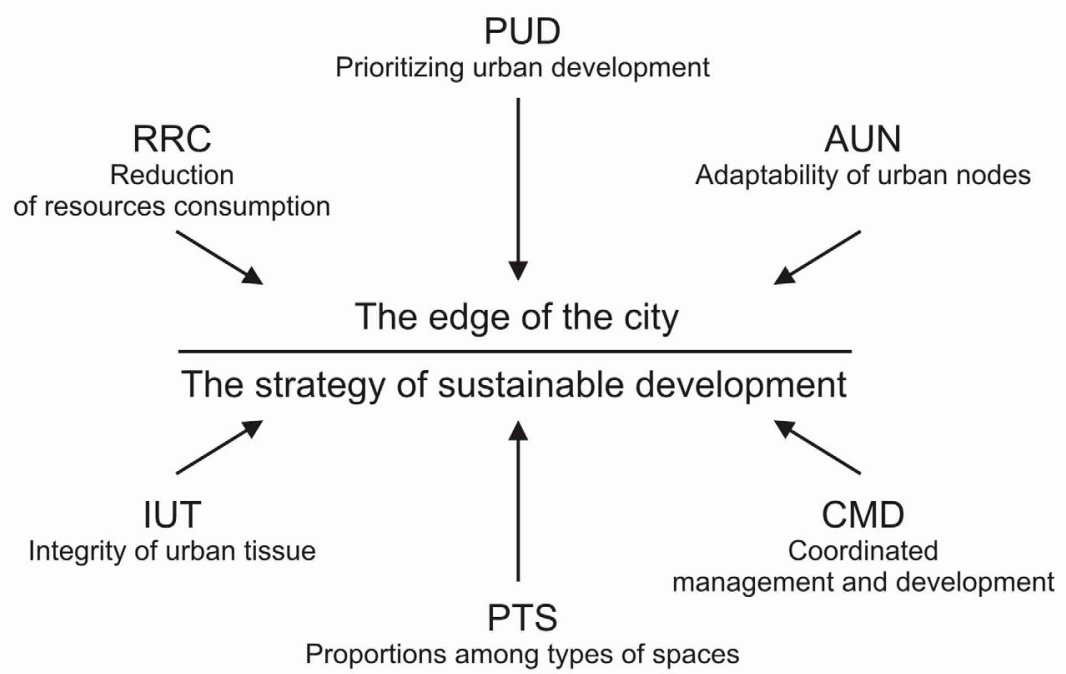

Figure 1: The principal elements of a framework for sustainable strategy for suburban areas; author: Barelkowski 2012.

Last but not least, the liminal zones of the city have to be subject to particularly strong coordination efforts between administrative bodies and decision makers, with the inclusion of social groups, local communities, and neighbouring environs. The principle goal is to secure spatial management and spatial development (CMD) and at the same time to assure solid social participation, including influence on decisions, and to extend the structures as 
components of technological corridors not only in the city, but also between the city and suburbs, and furthermore to the region, to negotiate and establish priorities which simultaneously reduce conflicts and contradictory effects.

The greatest gap in the system of implementing sustainable mechanisms may be located between strategic large scale planning and local interventions, with master planning included. This shift from general goals to particular tasks and stimulation of real results is only partially (and only in some cases) met with satisfactory in-depth analysis and attempts to connect all necessary tendencies and processes, to translate the general into detailed strategies, to diagnose the influence of limitations on the entity (and vice versa), to hierarchize, and to establish proper means to monitor and evaluate. This can be seen well when analyzing both strategic and local documents that municipal administration is currently working with, with the exclusion of some exceptional cases.

In Poland, the significant impact on regional space large agglomerations have is reflected in three-tier organization of administration - voivodship, county, and community levels. While spatial development strategy and plans concerning the entire region are elaborated by the voivodship department, for the two latter levels documents for large cities are formulated by the municipal board, and neighbouring communities define their own plans on the lowest level. The principles of urban development are defined in the strategy and multiple accompanying documents, while their implementation in space is elaborated in a study of spatial conditions and development. Social, economic, cultural goals, explicitly described in the strategy, are reinterpreted and - if proper methodology is applied - inserted in spatial regulations. However, the compulsory task to establish the coordinated shape of spatial development appears to have an effect on the study when most of the strategic documents have already been carried out. Instead of solving spatial problems, municipalities and neighbouring communities participate in this power play. What's more, the regional initiatives' implementation is particularly difficult to get organized and performed efficiently - scopes of competences, different statuses, and other issues are problematic.

Despite the fact that Poznan, a city of over 550,000 inhabitants, inherited a particularly well structured spatial structure which was the result of both good planning and gradual, evolutionary growth throughout its history of over 750 years, since its location in medieval times, these benefits are hardly noted within outer, suburban areas. Its central role in the region of Greater Poland caused, like in many similar cases worldwide, especially Europe, the emergence of correlated communities with continuous (sub)urban tissue comprising Swarzedz, Lubon, Suchy Las, Czerwonak, and others. Dynamic processes in these peripheral areas resulted in low quality developments, incidental coexistence of contradictory types of use, and dissonant spatial structures. These effects were even amplified when it appeared that commercial developments outpaced the reaction of authorities and market driven developments seized vital spaces, would-be buffers for future infrastructure, improvement of media and transportation systems. Large vacant, unwanted areas which were neither greeneries, agricultural land, nor places attractive for developers remained untouched. Bordering communities 
were at first eager to absorb estates migrating outside the city borders, but after a few years the underdeveloped road system, infrastructure, and most of all the unbalanced functional shift disarranged the performance of many neighbouring communities. On one hand, Poznan faces the outflow of inhabitants and problems with proper channelling of its developmental potential, on the other hand communities living in suburbs outside the administrative jurisdiction of Poznan are disappointed with the course transformation of their own environment took, changing these suburbs into typical bedroom communities, stripped of even the most basic public service areas, community centres, local scale commercial zones.

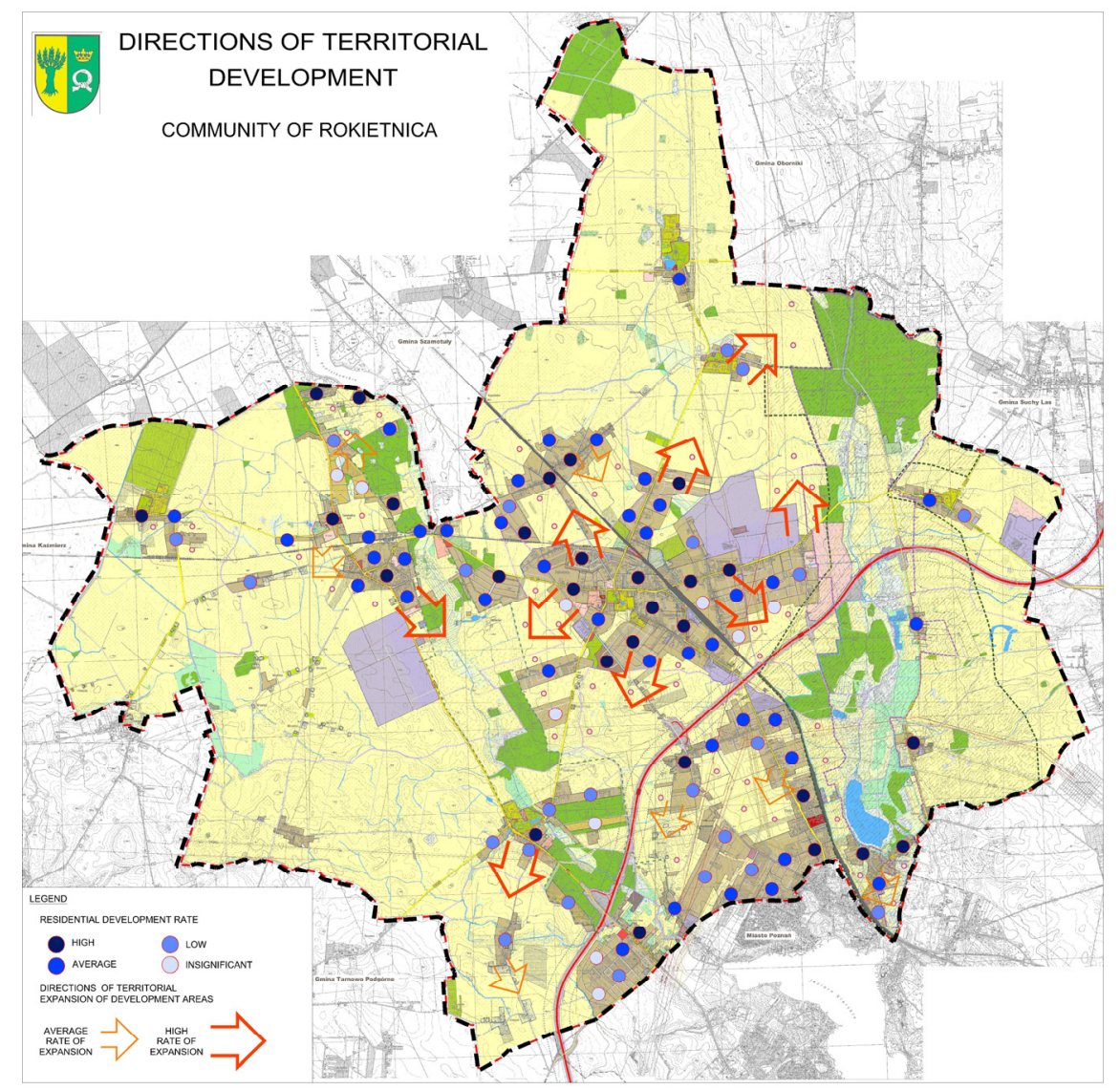

Figure 2: Excerpt from research: expansion of spatial development in Rokietnica community; authors: Barelkowski et al. 2011.

The research, conducted in three neighbouring communities of Poznan, indicated clearly that on both sides - within the city of Poznan and in the communities of Rokietnica, Suchy Las as well as the community of Oborniki - 
the city's edge was a place of chaotic struggle instead of coordinated effort and negotiated conditions [7]. Both sides were only slightly interested in what course spatial management and spatial attribution took in planning activities in neighbouring territories in regard to the current and most appropriate directions and needs of communities. The results were observed only "as is", with nothing being noted down but the distribution of particular spatial programmes. The city was unsuccessful in reasonable continuation and filling of spaces which are no longer used agriculturally and remain inside the city borders, communities were unable to maintain decent conditions for agricultural production and environmental assets allowing for dispersed settlement locations and abandoning completely the task of creating public spaces, integrating spaces.

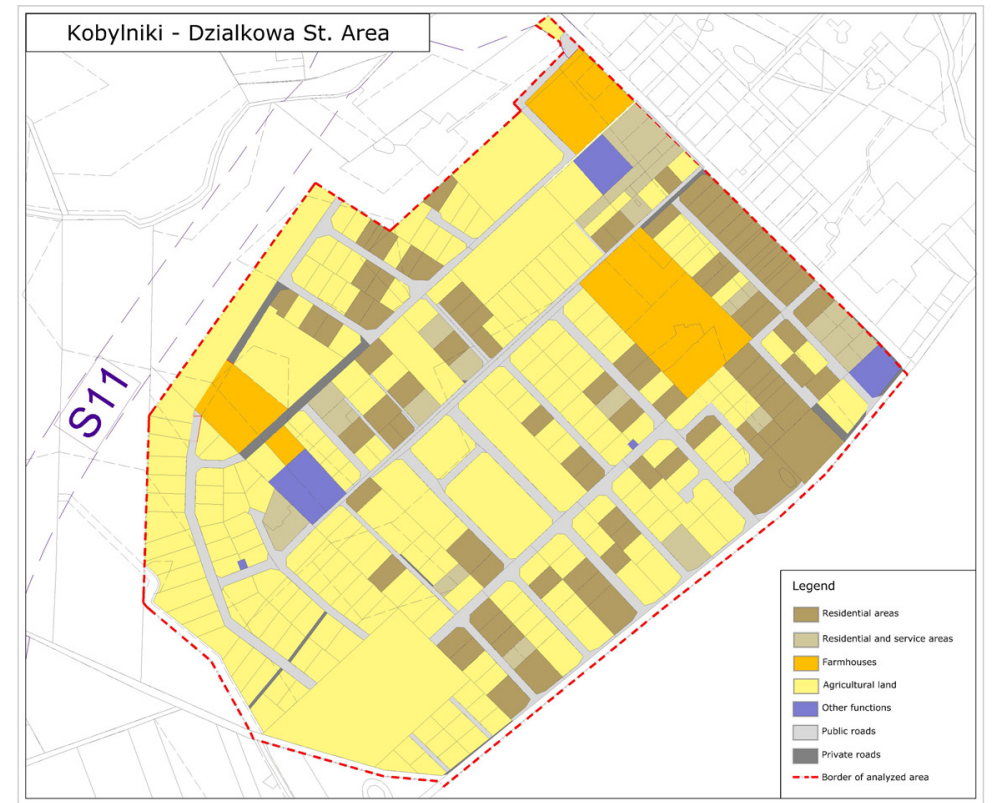

Figure 3: Excerpt from research: detailed study of spatial transformations in Kobylniki area, border of Poznan; authors: Barelkowski et al. 2011.

The ostensible advantages of liberal development policy appeared to become a detriment to many spaces, hampering not only places of particular development, but also other related areas, decreasing their potential, market value, and attractiveness. The communities, eager to improve their budgets with increased land value tax were unable to perform this operation correctly within 5 years and noted incomes 2 to 4 times lower than expected. Poznan, looking from another perspective, in the span of 20 years allowed the generation of a gigantic increase of individual transportation flow, causing congestion on a scale unprecedented before, in turn becoming the worst city in Poland in terms of congestion. Of course, focusing on negative tendencies herein does not bring justice to the complex evaluation of the quality of space in Poznan, but evidently 
the attempts to solve the problems of the edge of Poznan only slightly touched issues of IUT and PTS, leaving remaining postulates unimplemented.

What has to be noted is the fact that Poznan here is an exemplary, almost generic case (due to the lack of place to discuss details in this paper), reflecting many tendencies observed in Poland as well as in many cities of Central and Eastern Europe, not to mention some parts of Western Europe, too.

\section{Final thoughts}

The problems presented in this article refer most of all to how to achieve sustainability in peripheral urban areas. Although formulated as general rules and general principles, they offer a pragmatic and solid set of criteria that can be easily supported by parameters, and thus unambiguously verified.

The problem of method is significantly different from the problem of theoretical philosophy. Although one may argue whether the concept of continuity or the idea of primacy of adaptiveness and responsiveness should dominate, given the prudent advocate of the first with the inclusion of the rule primum non nocere, it may be concluded that these issues are of secondary importance in comparison to proper methodology in analyzing, negotiating and concluding the directions, spatial planning for crucial urban components must take. Therefore it is very important to implement know-how with learn-to-know policy, which is simply to implement systemic feedback, validation and multicollective discourse on planning issues.

The future of our cities lies in those fragile peripheral places. Amorphous, overlooked, underestimated, these large areas present great potential to the condition of cities and have a significant share in the ability of the city to transform the urban environment into a sustainable one. It is more a question of order of organization than the physical order of space, with the former being a precedent of the latter. But without the organization, the order is replaced with energy consuming, dispersed, expensively equipped with infrastructure, impoverished or substandard spaces.

\section{References}

[1] Hall, P., Cities in Civilization, Phoenix Giant: London, 1998. The description of the planning tasks undertaken by Hausmann.

[2] IUCN/UNEP/WWF, Caring for the Earth. A Strategy for Sustainable Living, http://coombs.anu.edu.au/ vern/caring/caring.html, p. 9, retrieved on 30 Dec 2011.

[3] Nijenhuis, W., City frontiers and their disappearance. Architectural Design Profile: The Periphery, No 108, pp. 13-17, 1994.

[4] Zaera Polo, A., Order out of Chaos. Architectural Design Profile: The Periphery, No 108, pp. 25-29, 1994.

[5] Gleeson, B. and Low, N., Is Planning History?. Urban Planning in a Changing World, ed. R. Freestone, E\&FN SPON: London, pp. 269-284, 2000 . 
[6] Koolhaas, R., Atlanta. Shaping the City. Studies in History, Theory and Urban Design, eds. R. El-Khoury and E. Robbins, Routledge: New York and London, pp. 5-13, 2004. Koolhaas analyzes the example of Atlanta to explain the generic urban space of contemporary city. Its placelessness, anonymity, dehumanization provides rightful basis for its contesting, however.

[7] Barelkowski, R., Suburbia as a battlefield: between society, environment and planning strategies. The Sustainable City VI. Urban Regeneration and Sustainability, eds. C. A. Brebbia, S. Hernandez and E. Tiezzi, WIT Press: Southampton and Boston, pp. 371-382, 2010. 